\title{
FAKTOR - FAKTOR YANG MEMPENGARUHI KEPADATAN KENDARAAN DENGAN KANDUNGAN KARBON MONOKSIDA (CO) DI KOTA MAKASSAR TAHUN 2019
}

Anisa Pratiwi ${ }^{1}$ dan Zaenab ${ }^{2}$

1,2, Jurusan Kesehatan Lingkungan Poltekkes Kemenkes Makassar

*pratiwianisa17@gmail.com

\begin{abstract}
The research of the vehicle density on Jalan Sultan Alauddin and the Hertasning from the four points of the vehicle density obtained in point two in morning and evening is said to be dense because the area is on for 1 hour and on the measurement of Karbo monoxide in the getaway from IE I results show results 3,085.71 ug/Nm3, point II shows the result i.e. 8,226.57 ug/Nm3, point III shows the results i.e. 3,885.71 ug/Nm3, point IV shows the result i.e. 2,285.71 ug/Nm3. Based on the results of the study it can be concluded that the levels of carbon monoxide (CO) on the border of Gowa Makassar, Sultan Alauddin Talasalapang, Hertasning Toddopuli, and Aeroppala Hertasning still under standard quality raw. It is recommended to Makassar City Government conducts tree planting by the roadside to reduce carbon monoxide levels in the air.
\end{abstract}

Keywords: air quality, Vehicle Density and carbon monoxide (CO)

ABSTRAK

Hasil penelitian kepadatan kendaran pada jalan Sultan Alauddin dan jalan Hertasning dari ke empat titik didapatkan kepadatan kendaraan yaitu pada titik dua yaitu pada pagi dan sore hari dikatakan padat karena pada daerah tersebut pada selama 1 jam dan pada pengukuran Karbo monoksida di dapatkan hasil yaitu titk I menunjukkan hasil 3,085.71 ug/ $\mathrm{Nm}^{3}$, titik II menunjukkan hasil yaitu $8,226.57 \mathrm{ug} / \mathrm{Nm}^{3}$, titik III menunjukkan hasil yaitu $3,885.71 \mathrm{ug} / \mathrm{Nm}^{3}$, titik IV menunjukkan hasil yaitu 2,285.71 $\mathrm{ug} / \mathrm{Nm}^{3}$.Berdasarkan hasil penelitian dapat disimpulkan bahwa kadar Karbon Monoksida (CO) pada jalan perbatasan Gowa Makassar, Sultan Alauddin Talasalapang, Hertasning Toddopuli dan Aeroppala Hertasning masih dibawah standar baku mutu. Disarankan kepada Pemerintah Kota Makassar melakukan penanaman pohon di pinggir jalan untuk mengurangi kadar Karbon Monoksida di udara.

Kata Kunci : Kualitas udara, Kepadatan Kendaraan dan Karbon Monoksida (CO)

\section{PENDAHULUAN}

Indonesia merupakan salah satu negara berkembang yang tidak lepas dengan berkembangnya teknologi. Berbagai inovasi teknologi telah digunakan untuk memudahkan berbagai aktivitas manusia. Salah satu teknologi yang berkembangnya cukup pesat adalah bidang transportasi. Transportasi yang dimaksud meliputi transportasi udara, air dan darat. $\mathrm{Di}$ antara ketiga transportasi tersebut, transportasi darat banyak di gunakan oleh masyarakat.

Aktivitas transportasi di jalan raya semakin meningkat disebabkan oleh pertumbuhan penduduk, peningkatan pendapatan dan daya tarik kota yang sangat pesat. Angka kepemilikan kendaraan bermotor di Indonesia menunjukkan kecenderungan yang terus meningkat, sehingga timbul tiga persoalan yang sangat serius, yakni kemacetan, meningkatnya bahan bakar dan semakin parahnya tingkat pencemaran udara akibat dari emisi gas buang yang di hasilkan (Dirga , 2014)

Data dari Gabungan Industri Kendaraan Bermotor Indonesia (Gaikindo) dan Asosiasi Indsutri Sepeda Motor Indonesia (AISI) menunjukkan jumlah populasi kendaraan bermotor di Indonesia di tahun 2010 mencapai 50.824.128 unit (Arianto , 2011), berdasarkan Badan Pusat Statistik (BPS) Indonesia, jumlah sepada motor pada tahun 2011 yaitu 68.839.341 unit.

Polusi udara yang ditimbulkan oleh kendaraan bermotor sebesar $70-80 \%$ sedangkan pencemaran udara akibat industri dan lainnya hanya $20-30 \%$ saja. Besarnya presentase pencemaran udara dari sumber transportasi di Indonesia adalah 70,50 \% CO : $18,34 \%$, HC : 8,89 \%, Nox : 1,33\% partikel. Gas - gas tersebut sangat berbahaya bagi manusia, selain dampak negatif pada kesehatan, juga berdampak negatif terhadap ekosistem atau lingkungan pada umumnya (Wardhana , 2001)

Bertambahnya jumlah sepeda motor ini akan berdampak segala aspek kehidupan masyarakat. Disatu pihak menunjukkan peningkatan kualiatas kehidupan masyarakat dipihak lain akan menambah terjadinya pencemaran udara, hal ini disebabkan oleh gas buang yang di timbulkan dari kendaraan bermotor.

Kota Makassar merupakan salah satu kota yang mengalami kemajuan yang sangat pesat. Sebagai kota yang mengalami kemajuan pesat pasti memiliki beberapa masalah perkotaan, salah satu diantaranya adalah masalah kemacetan lalu lintas di jalan raya. Kemacetan ini timbul karena semakin tingginya volume kendaraan pribadi yang tidak dibarengi dengan pembangunan infrastruktur yang cepat dan kurang disiplinnya para pengendara dalam menggunakan kendaraannya. Di kota Makassar jumlah kendaraan roda 2 meningkat $13-14 \%$ per tahun dan roda 4 meningkat $8-10 \%$ per tahun. Jumlah kendaraan roda dua maupun roda empat mecapai 2,4 juta ( 1,1 juta motor dan 1,3 
juta mobil) lebih tinggi dari jumlah penduduk Kota Makassar sebanyak 1,7 juta jiwa pada tahun 2017 (Pusat Data dan Informasi Kementerian Perhubungan Kota Makassar, 2017).

\section{Variabel Penelitian}

1. Variabel Bebas dalam penelitian ini yaitu Kepadatan kendaraan, suhu, kelembaban, kecepatan angin.

2. Variabel Terikat dalam penelitian ini yaitu Karbon Monoksida

3. Variabel Pengganggu dalam penelitian ini yaitu Musim

Populasi

Populasi dalam Penelitian ini adalah

Konsetrasi kandungan Karbon monoksida di jalan Sultan Alauddin dan jalan Hertasning.

\section{Sampel}

Teknik yang digunakan dalam penentuan sampel yaitu non probability sampel (ditentukan) secara sampling Purposive (pertimbangan) khusus. Sampel pada penelitian in yaitu jalan Sultan Alauddin dan jalan Hertasning Kota Makassar yang masing - masing 4 titik pengambilan sampel dilakukan 2 kali. Lokasi penelitian dilakukan pada titik I perbatasan Gowa-Makassar, titik II pertigaan Talasalapang Sultan Alauddin , titik III perempatan Hertasning Toddopuli, titik IV Aroepala Hertasning.

Pertimbangan penelitian mengambil sampel yaitu karakteristik sampel tiap jalan tidak sama (Non-homogen).

\section{Pengumpulan Data}

\section{a) Data primer}

Data primer diperoleh dengan melakukan observasi dan pengkuran kandungan Karbon monoksida. Observasi lapangan dengan pengukuran langsung kandungan Karbon monoksida serta melihat langsung kondisi kawasan jalan Sultan Alauddin dan jalan Hertasning kota Makassar.

\section{b) Data Sekunder}

Data sekunder yang berfungsi sebagai data pendukung antara lain literatur, buku, jurnal yang berhubungan dengan penelitian ini

\section{Analisa Data}

Dari hasil penelitian pengukuran dilapangan dan hasil pemerikasaan di laboratorium yang diperoleh pada saat penelitian di analisa secara deskriptif dalam bentuk tabel di sertai dengan analisa informasi antara variabel serta uraian yang di dasari pada dasar teori pendukung.

\section{Hasil Penelitian}

Penelitian yang dilaksanakan 4 titik meliputi, titik I yaitu Perbatasan Gowa Makassar, titk II berada di jalan Talasalapng Sultan Alauddin, titik III berada di jalan Hertasning Toddopuli, dan titik IV berada di jalan Aeroppala Hertasning Kota Makassar.Pembagian waktu dilakukan untuk

membandingkan hasil pengukuran kadar kualitas udara Karbon Monoksida (CO). Pada pagi hari kondisi jumlah kendaraan masih kurang, sore hari kondisi jumlah kendaraan mulai ramai bahkan sangat macet. Berdasarkan penelitian yang dilakukan pada jalan Sultan Alauddin dan Hertasning Kota Makassar kepadatan kendaraan dan hasil pengukuran Karbon Monoksida sebagai berikut

Tabel 1

Kepadatan kendaraan di jalan Sultan Alauddin dan Hertasning Kota Makassar Tahun 2019

\begin{tabular}{ccccc}
\hline & \multicolumn{2}{c}{ Waktu } & \multicolumn{2}{c}{ Kepadatan } \\
\cline { 2 - 5 } Lokasi & Pagi & Sore & Pagi & Sore \\
\hline Titik I & 8.00 & 15.00 & TP & $\mathrm{P}$ \\
Titik II & 09.05 & 16.05 & $\mathrm{P}$ & $\mathrm{P}$ \\
Titik III & 10.15 & 17.10 & $\mathrm{P}$ & $\mathrm{TP}$ \\
Titik IV & 11.08 & 18.10 & TP & $\mathrm{P}$ \\
\hline Keterangan: $P$ & $:$ Padat & & \\
& TP & $:$ Tidak Padat & &
\end{tabular}

Tabel 2

Hasil Pengukuran Karbon Monoksida (CO) di jalan Sultan Alauddin dan Hertasnin Kota Makassar Tahun 2019

\begin{tabular}{ccc}
\hline & \multicolumn{2}{c}{ Waktu } \\
\cline { 2 - 3 } Lokasi & Pagi & sore \\
\hline \multirow{2}{*}{ Titik I } & $3,085.71$ & $6,971.42$ \\
& ug/ $/ \mathrm{Nm}^{3}$ & $\mathrm{ug} / \mathrm{Nm}^{3}$ \\
Titik II & $8,228.57$ & $7,085.71$ \\
& $\mathrm{ug} / \mathrm{Nm}^{3}$ & $\mathrm{ug} / \mathrm{Nm}^{3}$ \\
Titik III & $3,885.57$ & \\
& $\mathrm{ug} / \mathrm{Nm}^{3}$ & $6,400 \mathrm{ug} / \mathrm{Nm}^{3}$ \\
Titik IV & $2,285.71$ & \\
& $\mathrm{ug} / \mathrm{Nm}^{3}$ & $\mathrm{ug} / \mathrm{Nm}^{3}$ \\
\hline
\end{tabular}

Sumber: Data primer 2019

Tabel.3

Hasil Pengukuran Suhu di jalan Sultan Alauddin dan Hertasning Kota Makassar Tahun 2019

\begin{tabular}{lcc}
\hline & \multicolumn{2}{c}{ Waktu } \\
\cline { 2 - 3 } Lokasi & Pagi & Sore \\
\hline Titik I & $31,3^{\circ} \mathrm{C}$ & $33,3^{\circ} \mathrm{C}$ \\
Titik II & $33,4^{\circ} \mathrm{C}$ & $32,7^{\circ} \mathrm{C}$ \\
Titik III & $33,8^{\circ} \mathrm{C}$ & $32,7^{\circ} \mathrm{C}$ \\
Titik IV & $36,60 \mathrm{C}$ & $34,2^{\circ} \mathrm{C}$ \\
\hline
\end{tabular}

Sumber: Data primer 2019 
Tabel 4

Hasil Pengukuran kelembaban dijalan Sultan Alauddin dan Hertasning Kota Makassar Tahun 2019

\begin{tabular}{ccc}
\hline \multirow{2}{*}{ Lokasi } & \multicolumn{2}{c}{ Hasil Pengukuran } \\
\cline { 2 - 3 } & Pagi & Sore \\
\hline I & $56 \%$ & $58 \%$ \\
II & $52 \%$ & $59 \%$ \\
III & $44 \%$ & $59 \%$ \\
IV & $51 \%$ & $58 \%$
\end{tabular}

Sumber: Data primer 2019

Tabel 5

Hasil Pengukuran Kecepatan angin sultan alauddin dan Hertasning Kota Makassar Tahun 2019

\begin{tabular}{ccc}
\hline \multirow{2}{*}{ Lokasi } & \multicolumn{2}{c}{ Hasil Pengukuran } \\
\cline { 2 - 3 } & \multicolumn{1}{c}{ Pagi } & Sore \\
\hline I & $1,18 \mathrm{~m} / \mathrm{d}$ & $4,10 \mathrm{~m} / \mathrm{d}$ \\
II & $1,47 \mathrm{~m} / \mathrm{d}$ & $2,14 \mathrm{~m} / \mathrm{d}$ \\
III & $1,22 \mathrm{~m} / \mathrm{d}$ & $1,72 \mathrm{~m} / \mathrm{d}$ \\
IV & $1,97 \mathrm{~m} / \mathrm{d}$ & $2,15 \mathrm{~m} / \mathrm{d}$
\end{tabular}

Sumber: Data primer 2019

\section{PembahasanPenelitian}

\section{Kepadatan Kendaraan}

Berdasarkan tabel 1 kepadatan kendaraan dari empat titik pada jalan Sultan Alauddin dan Hertasning, menunjukkan hasil kepadatan kendaraan terdapat di jalan Sultan Alauddin Talasalapang yaitu titik dua. Titik dua dinyatakan padat kendaran pada pagi dan sore hari karena pada daerah tersebut terdapat pertigaan yang menyebabkan terjadinya pertemuan kendaraan dari jalur Talasalapang dan jalur Sultan Alauddin yang menyebabkan terjadinya kemacetan atau kepadatan dan aktivitas manusia seperti banyaknya pedagang kaki lima yang menjual di pinggir jalan raya dan pada daerah tersebut dekat dari universitas yang mahasiswanya memakirkan kendaraannya di pinggir jalan sehingga menyebabkan bertambah padatnya kendaraan di daerah tersebut. aktivitas manusia sangat erat kaitannya dengan transportasi sebagai alat penghubung dari satu tempat ke tempat yang lain. Alat transportasi mengeluarkan gas buang yang dapat membahayakan kesehatan manusia pada khususnya dapat mencemari lingkungan pada umumnya. Emisi gas buang dari kendaraan akan mengeluarkan Karbon monoksida (CO) yang merupakan gas pencemar udara yang utama, gas ini adalah polutan udara yang sangat besar, yang berefek langsung pada kesehatan manusia tetapi efeknya tidak berlangsung tampak dalam jangka waktu yang singkat.

Semakin banyaknya jumlah kendaraan, maka polusi udara akan semakin meningkat. Hal tersebut diiringi oleh tingkat kosentrasi Karbon monoksida (CO) yang semakin tinggi peningkatan karbon monoksida (CO) paling dominan disebabkan oleh aktifitas manusia terutama dari segi transportasi.(Fardiaz, 2008). Penelitian ini sejalan dengan penelitian Putri Ines Wijaya (2017) dengan judul Analisis Pencemaran Udara Akibat Kepadatan Jalan Lalu Lintas Di Kota Padang Tahun 2017 yang dinyatakan kepadatan kendaraan bermotor di Kota padang sangat padat tetapi sejalan dengan peluasan ruas jalan.

Pada pagi dan sore hari dengan kondisi suhu dan kelembaban udara yang tinggi akibat sinar matahari yang diterima sehingga akan mengakibatkan pemuaian udara. Hal ini menyebabkan terjadinya dispersi polutan sehingga konsentrasi $\mathrm{CO}$ akan tinggi, dan kecepatan angin merupakan faktor penting dalam pendispersian polutan. Ketika kecepatan angin stabil maka penyebaran polutan akibat kepadatan kendaraan lebih cepat terjadi dan kosentrasi menumpuk disekitaran daerah padat kendaraan.

\section{Karbon Monoksida (CO)}

Berdasarkan tabel 2 hasil pengukuran kandungan Karbon Monoksida (CO) di jalan Sultan Alauddin dan Hertasning di dapatkan hasil kandungan Karbon Monoksida tertinggi yaitu di jalan Sultan Alauddin Talasalapang menunjukkan pada pagi hari $8,228.57 \mathrm{ug} / \mathrm{Nm}^{3}$ dan sore hari $7,085.71$ $\mathrm{ug} / \mathrm{Nm}^{3}$ dengan suhu pada pagi hari $33,4^{\circ} \mathrm{C}$ dan sore hari $32,7{ }^{\circ} \mathrm{C}$, kelembaban pada pagi hari $52 \%$ dan sore $59 \%$, kecepatan angin pagi hari 1,47 m/d dan sore 2,14 m/d. Dan hasil pengukuran kandungan Karbon Monoksida terendah pada titik tiga di jalan Aeroppala Hertasning yaitu 2,285.71 $\mathrm{ug} / \mathrm{Nm}^{3}$ dan sore hari 5,714.28 ug/ $\mathrm{Nm}^{3}$ dengan suhu pada pagi hari $36^{\circ} \mathrm{C}$ dan sore $34{ }^{\circ} \mathrm{C}$, kelembaban pada pagi hari $51 \%$ dan sore $58 \%$, kelembaban pagi hari $1,97 \mathrm{~m} / \mathrm{d}$ dan sore 2,15 m/d.

Pengukuran kandungan Karbon Monoksida ini hasil tertinggi berada pada pagi dan sore hari di titik dua jalan Sultan 
Alauddin Talasalapang karena dimana kosentrasi meningkat pada jam padat kendaraan dan dapat juga di pengaruhi oleh suhu, kelembaban dan kecapatan angin. suhu udara yang tinggi akan mempercepat terjadinya reaksi gas buang di udara karena udara akan merambat ke atas sehingga udara yang mengandung polutan akan mencemari udara. Peningkatan gas Karbon Monoksida (CO) hal ini berkaitan erat dengan laporan WHO (1992) dinyatakan paling tidak $90 \%$ dari Karbon Monoksida di udara perkotaan berasal dari emisi kendaraan. Penelitian ini sejalan dengan penelitian Muzayyid (2014) dengan judul Studi Kosentrasi Kadar Karbon Monoksida (CO) Di jalan A.P Petarani Kota Makassar Tahun 2014 yang dinyatakan masih memenuhi sesuai standar yang telah ditetapkan.

Suhu udara yang tinggi akan menyebabkan bahan pencemar dalam udara berbentuk partikel menjadi kering dan ringan sehingga bertahan lama di udara, terutama pada musim kemarau dimana keadaan udara lebih kering sehingga polutan udara pada keadaan musim kemarau cenderung lebih tinggi karena terjadinya pengenceran polutan di udara. Hubungan antara suhu udara terhadap kosentrasi Karbon Monoksida semakin tinggi, hal ini terjadi karena adanya suhu tinggi akan mempercepat terjadinya penguraian (disosiasi) gas Karbon Monoksida. Semakin tinggi suhu udara maka jumlah gas Karbon Monoksida yang menjadi $\mathrm{C}$ dan $\mathrm{O}$ akan semakin banyak. (Mukono, 2011)

Suhu udara akan berfluktuasi dengan nyata selama setiap periode 24 jam. Fluktuasi suhu udara berkaitan erat dengan proses pertukaran energi yang berlangsung di atmosfer. Pada sore hari sebagian dari radiasi matahari akan diserap oleh gas-gas atmosfer dan partikel padat yang melayang di atmosfer. Serapan energi radiasi matahari ini akan menyebabkan suhu udara meningkat. Suhu udara harian maksimum tercapai beberapa saat setelah intensitas cahaya maksimum tercapai pada saat berkas cahaya jatuh tegak lurus yakni pada saat sore hari. Sedang suhu udara minimum pada saat menjelang matahari terbit.

$\mathrm{Hal}$ ini disebabkan oleh keadaan atmosfer yang tidak stabil dimana pada pagi hari sifat udara bergerak secara vertikal sehingga terjadi turbelensi. Adanya turbelensi akan memancing dispersi sehingga pencemar dapat akan naik, terekspansi menjadi lebih encer atau ringan dan lebih dingin. Sedangkan pada kondinsi sore atmosfer bersifat stabil dimana sifat udara bergerak secara horizontal yang menahan polutan tidak bergerak naik sehingga polutan terdispersi. Selain karena sifat suhu,kelembaban dan kecepatan angin tersebut. Kecepatan angin pada dasarnya ditentukan oleh perbedaan tekanan udara antara tempat asal dan arah angin sebagai faktor pendorong. Secara umum polutanpolutan di atmosfer terdispersi dalam 2 cara yaitu melalui kecepatan angin dan turbulensi atmosfer. Turbulensi menyebabkan terjadinya aliran udara melalui 2 cara yaitu pusaran termal dan pusaran mekanis (Amiroh, 2004).

Banyaknya aktivitas dijalanan ini berarti pengaruh kendaraan sangat penting dalam peningkatan gas Karbon monoksida ,pengaruh Karbon monoksida pada sore lebih tinggi jika dibandingkan dengan pengukuran pagi. pada sore hari, polutan di udara terakumulasi sehingga nilainya akan lebih besar. hal ini dikarenakan terdapatnya daerah - daerah tertentu pada beberapa titik yang menyebabkan padatnya kendaraan sehingga kandungan Karbon monoksida meningkat.

Bila dibandingkan dengan standar baku mutu udara ambien Peraturan Pemerintah Republik Indonesia No.41 Tahun 1999 Maka semua titik pengukuran kandungan Karbon Monoksida (CO) masih dibawah standar baku mutu dengan nilai standar $30.000 \mathrm{ug} / \mathrm{Nm}^{3}$. Namun dari hasil pengukuran kandungan Karbon Monoksida menunjukkan kualitas udara Karbon Monoksida (CO) di jalan Sultan Alauddin dan Hertasning masih dalam keadaan aman dari segi baku mutu udara ambien untuk masyarakat yang melakukan aktivitas di jalan Sultan Alauddin dan Hertasning.

Karbon monoksida adalah senyawa yang sangat beracun namun tidak berwarna dan hampir tidak berbau, sehingga sangat membahayakan kehidupan. Oleh karena itu di pantau secara terus menerus. Keberadaannya diudara sebagai akibat dari pembakaran yang tidak sempurna dari bahan organik seperti kayu, batu-bara, kertas, minyak serta pembakaran bermotor yang memakai bahan bakar. (Wardhana, 2004). Hasil pembakaran kendaraan yang memakai bahan bakar bensin di udara ambient mengandung Karbon monoksida berkisaran $1-10 \%$ tergantung dari operasi mesin. Sedangkan operasi mesin diesel pada udara ambient hanya mengandung 
kira - kira 0,1\% Karbon monoksida (CO). (Achmad, 2004).

Pencemaran udara akan meningkatkan probabilitas gangguan kesehatan pada manusia yang sehat karena pada umumnya polutan udara berbentuk gas dan tidak dapat dilihat dengan mata biasa. Bahkan untuk polutan Karbon monoksida, tidak menghasilkan bau. Manusia yang sehat akan terpapar Karbon monoksida secara tidak sadar namun perlahan mengalami gejala sakit ringan seperti pusing, sakit kepala atau mual. Gejala terpapar Karbon monoksida yang menyerupai penyakit lain akan menyebabkan manusia tersebut semakin tidak menyadari bahwa dirinya telah terpapar dan dapat salah mendiagnosa sakit yang dideritanya. Karena yang dibutuhkan individu saat terpapar Karbon monoksida adalah udara bersih dan segar untuk mengantikan Karbon monoksida yang terikat di hemoglobin.

Hemoglobin berfungsi untuk mengangkut oksigen dalam darah kemudian membentuk carboxyhemoglobin (COHb). Karbon monoksida mampu mengikat hemoglobin sebanyak 220 kali lebih kuat dibandingkan dengan daya ikat antara hemoglobin dan oksigen, sehingga menyebabkan berkurangnya kapasitas darah dalam mengangkut oksigen. Secara langsung hal ini akan menyebabkan pasokan oksigen ke seluruh tubuh menurun, sehingga melemahkan kontraksi jantung dan menurunkan volume darah yang didistribusikan. Hal ini kemudian akan mempengaruhi fungsi organ-organ tubuh seperti otak, hati, dan pusat saraf. $70 \%$ atau lebih $\mathrm{COHb}$ dalam darah akan menyebabkan kematian.

Telah lama diketahui bahwa kontak antara manusia dengan Karbon monoksida pada kosentrasi tinggi dapat menyebabkan kematian. Tetapi ternyata kontak dengan Karbon monoksida pada kosentrasi yang relative rendah (100 ppm atau kurang) juga dapat mengganggu kesehatan. Pertolongan bagi yang keracunan gas Karbon monoksida pada tingkat yang relatif masih ringan dapat dilakukan dengan ke tempat yang udara terbuka (segar). (Wardhana, 2004)

\section{Kesimpulan dan Saran}

1. Kesimpulan

Dari hasil penelitian maka dapat disimpulkan sebagai berikut:

a. Kepadatan kendaraan mempengaruhi keberadaan kandungan Karbon monoksida di jalan Sultan Alauddin dan Hertasning.

b. Kadar Karbon monoksida (CO) di jalan Sultan Alauddin dan Hertasning masih berada dibawah standar baku mutu yang telah ditetapkan peraturan Pemerintah Republik Indonesia No.41 Tahun 1999 yaitu $30.000 \mathrm{ug} / \mathrm{Nm}^{3}$.

c. Suhu dapat mempengaruhi peningkatan kandungan Karbon monoksida di jalan Sultan Alauddin dan Hertasning.

d. Kelembaban dapat mempengaruhi peningkatan kandungan Karbon monoksida di jalan Sultan Alauddin dan Hertasning.

e. Kecepatan angin dapat mempengaruhi peningkatan kandungan Karbon monoksida di jalan Sultan Alauddin dan Hertasning.

\section{Saran}

Berdasarkan hasil penelitian ini, diharapkan pemerintah Kota Makassar melakukan penanaman pohon di pinggir jalan agar peningkatan gas buang dari emisi kendaraan tidak mencemarii udara terkhususnya di jalan Sultan Alauddin Talasalapang dan untuk peneliti selanjutnya dalam pengambilan data lebih memperhatikan jumlah kendaraan dan faktor-faktor yang mempengaruhi dalam pengukuran kualitas Udara.

\section{Daftar Pustaka}

Arianto, A., 2011, Kendaraan Bermotor Di Indonesia Terbanyak Di ASEAN,Tempo 2011

Achmad Rukaesih, 2004. Kimia Lingkungan. Yogyakarta: Andi

Aliyana Maulidsyah Salam. 2018. Analisa kualitas udara pada kawasan parkiran di Mall Panakukang square Kota Makassar. Makassar: Poltekkes Makassar Jurusan Kesehatan Lingkungan. (Skripsi tidak di terbitkan) 
Jurnal Sulolipu : Media Komunikasi Sivitas Akademika dan Masyarakat

Vol. 20 No. 12020

e-issn : 2622-6960, p-issn : 0854-624X

Atqiya Muslihati, 2016. Pengaruh Jumlah Kendaran Bermotor Terhadap Kualiats Udara Dan Pertumbuhan Tanaman Rhoeo Discolor.(Online) (http://repository.unhas.ac.id/bitstream/handle/123456789/19347/BAB\%20I.pdf?sequen $\mathrm{ce}=1$ diakses 26 januari 2019)

Amiroh, Kurnia, 2004. Studi Karakteristik Lalu Lintas Di Jalan Raya Kaligawe Semarang, Tugas Akhir Fakultas Teknik Unissula Semarang.(Online)(http://ejournal3.undip.ac.id/index.php/jkm diakses 07 mei 2019)

Citra Yunita. 2016. Studi Konsentrasi Karbon Monoksida (CO) Udara Di Kematan Ujung Pandang Kota Makassar. Makassar: Poltekkes Kemenkes Makassar jurusan kesehatan lingkungan.(Skripsi tidak diterbitkan)

Depkes Republik Indonesia, 2009. Parameter Pencemaran Udara Dan Dampaknya Terhadap Kesehatan. Jakarta: Dirjen Bina Kesmas Depkes.

Dirga Ayusti. 2014. Analisa Kadar Emisi Gas Karbon Monoksida (CO) Dari Kenadaraan Bermotor Yang Melalui Penyerap Karbon Aktif Dari Kulit Buah Durian.Jurnal Departemen Kimia Fakultas Matematika Dan Ilmu Pengetahuan Alam (Online). hhtps://core.ac.uk/download/pdf/77619540.pdf diakses 13 Desember 2018)

Fardiaz, Srikandi. 1992. Polusi Air dan Udara. Yogyakarta:Kanisius

Fardiaz, Srikandi. 2008. Polusi Air dan Udara. Cetakan II. Jakarta: Kanisius

Herlina Loba. 2011. Studi Kandungan Karbon Monoksida (CO) Diruas Jalan Gunung Bawakaraeng Kota Makassar. Makassar: Poltekkes Kemenkes Makassar. (Skripsi tidak diterbitkan)

Indah Rahmadana. 2017. Analisi Konsentrasi Karbon Monoksida (CO) Dan Sulfur Dioksida $\left(\mathrm{SO}_{2}\right)$ Udara Pada Sumber Bergerak Di Jalan A.P Petarani Dan Jalan Rappocini Raya Kota Makassar. Poltekkes Kemenkes Makassar. (Skripsi tidak diterbitkan)

Ismail. 2002. Studi Konsentrasi Karbon Monoksida Pada Udara Dijalan Poros Sungguminasa Makassar Kab.Gowa. Makassar: Fakultas Kesehatan Masyarakat.Unhas.(Skripsi tidak diterbitkan)

Moestikahadi Soedomo. 2001. Pencemaran Udara . Kumpulan Karya IImiiah ITB.Bandung: ITB

Muh Alfian Nur. 2015. Gambaran Kadar karbon Monoksida (CO) Di Terminal Peti Kemas Pelabuhan Soekarno - Hatta Makassar. Makassar: Jurusan Kesehatan Lingkungan.(Skripsi tidak diterbitkan)

Muzyyid. 2014. Studi Konsentrasi Kadar Karbon Monoksidan (CO) Di Jalan A.P Petarani Kota Makassa. Jurnal Universitas Islam Negeri(UIN)AlauddinMakassar(Online)http://repositori.uinalauddin.ac.id/6604/1/MUZAYYID_ opt.pdf diakses 13 Desember 2018).

Mukono, H.J. 2003. Prinsip dasar kesehatan Lingkungan. Surabaya: Airlangga university press

Nurul Hikmah. 2016. Pengukuran Kadar Karbon Monoksida (CO) Pada Bestment Karebosi Link Makassar.Makassar: Jurusan Kesehatan Lingkungan Poltekkes Kemenkes Makassar.(KTI tidak di terbitkan)

Peraturan Pemerintah Republik Indonesia Nomor 41 Tahun 1999 Tentang Pengendalian Pencemaran Udara. 
Jurnal Sulolipu : Media Komunikasi Sivitas Akademika dan Masyarakat

Vol. 20 No. 12020

e-issn : 2622-6960, p-issn : 0854-624X

Putri Ines Wijaya. 2017. Analisis Pencemaran Udara Akibat Kepadatan Jalan Lalu Lintas Di Kota Padang. Jurnal Universitas Negeri Padang Program Studi Geografi Fakultas IImu Sosial. (Online) $\quad$ http://download.garuda.ristekdikti.go.id/article.php?articl= 779360\&val=12806\&title=\%20Analisis\%20Pencemaran\%20Udara\%20Akibat\%20Kepadatan \%20Jalan\%20Lalu\%20Lintas\%20di\%20Kota\%20Padang\%20(Studi\%20Kasus:\%20Karbon\% 20Monoksida\%20di\%20Jalan\%20Prof.Dr.Hamka,\%20Jalan\%20Khatib\%20Sulaiman,\%20dan \%20Jalan\%20Rasuna\%20Said). (Diakses 15 Juli 2019).

Sarudji, D. 2010. Kesehatan Lingkungan. Bandung: Karya Putra Darwati. Cetakan Pertama

Srikandi Fardiaz. 1992. Polusi Air Dan Udara. Pangan Dan Gizi Institut Pertanian Bogor 1992.

Sumantri, Arif. 20113. Kesehatan Lingkungan. Cetaka 2. Jakarta: Kencana Prenada Media Group.

Sinta Brigyta Pangerapan. 2018. Analisa Kadar Karbon Monoksida (CO) Udara Di Terminal Beriman Kota Tomohon. Jurnal Universitas Sam Ratulangi Manado Fakultas Kesehatan Masyarakat(Online)http://www.ejournalhealth.com/index.php/kesmas/article/viewFile/795/78 0. (Diakses Tanggal 16 Desember 2018).

Tresna Sastrawijaya. 2009. Pencemaran Udara. Jakarta: Rineka Cipta Jakarta

Wisnu Arya Wardhana. 2004. Dampak Pencemaran Lingkungan. Yogyakarta: Andi 